\title{
VBHF System Research Basing on the Technology of Fuzzy PID Control
}

\author{
Chun-Jian $\mathrm{Su}^{*}$ and Jun-min Zhao
}

College of Mechanical and Electronic Engineering, Shandong University of Science and Technology, Qingdao, 266590, China

\begin{abstract}
High precision in sheet metal stamping parts is required to control springback in sheet metal process; however, how to accurately predict and control the springback is a scientific problem for high-performance precision manufacturing. VBHF (Variable blank holder force) technology is an effective measure to control the springback of sheet metal, and the realization of the variable blank-holder force system is a difficulty. VBHF system mostly controls the flow of servo valve to control the pressure of ejection cylinder so as to control the blank-holder force. The stability and realtime factors are influenced greatly by the precision of the valve and the control current instantaneous changes. This paper quotes PID control module based on the technology of fuzzy to control the VBHF. Its principle is based on PID controller to add a fuzzy control module. Application of virtual instrument LabVIEW software incorporates the operating system and real-time data acquisition system. Through parameter, adjustment can meet the system's rapid, stable and robust requirements.
\end{abstract}

Keywords: Fuzzy theory, Parameter adjustment, PID control, The springback, VBHF.

\section{INTRODUCTION}

The traditional mold design to provide VBHF equipment generally involves spring, rubber and air pressure pad. All three of them provide the BHF (blank-holder force) curves respectively in oblique line, half parabola and straight line, as shown in Fig. (1). The first two curves increase with the increase in tensile trip. The latter, namely air pressure pad or hydraulic pressure pad, is provided for constant BHF. Best BHF trajectory for the sheet metal forming process opens downwards parabola and begins with the BHF (blank-holder force) to gradually increase, reaching a maximum point after

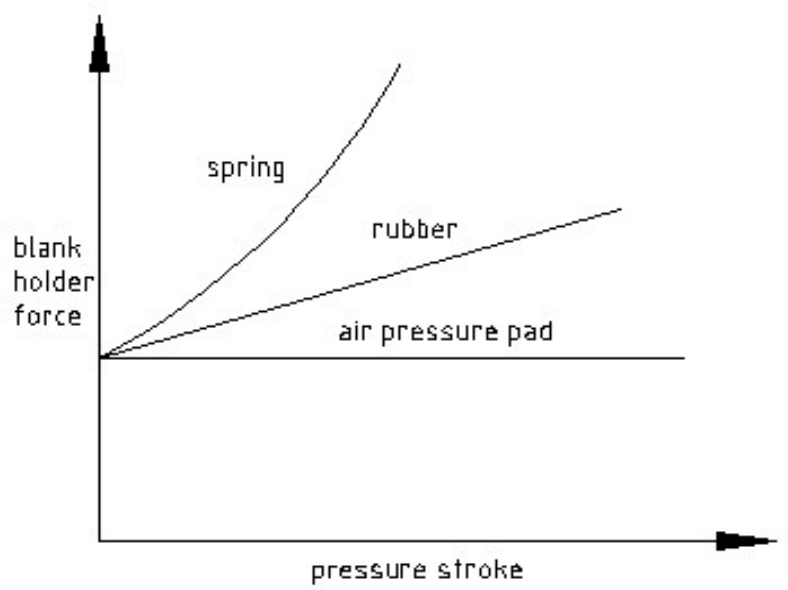

Fig. (1). Pressure element provides the BHF trajectory curve.

\footnotetext{
*Address correspondence to this author at the College of Mechanical and Electronic Engineering, Shandong University of Science and Technology, Qingdao 266590, China; Tel: 15020073591;

E-mail: suchunjian2008@163.com
}

the blank holder force decreases. It is clear that spring, rubber and air pressure pad influence BHF provided that under the control of best BHF, track requirements are not met. Obviously, spring, rubber and air cushion in the case do not control, provided that BHF cannot meet the requirement of optimum BHF trajectory $[1,2]$.

VBHF technology is a technology that by adjusting the air pressure and hydraulic pressure, makes the air pressure pad or hydraulic pressure pad provide BHF change with pressure stroke. It can effectively control the plastic flow by controlling the spring back of the sheet [3]. Fig. (2a) represents the workpiece with constant BHF, (2b) with VBHF, and as can be seen from the diagram, the workpiece using VBHF is of better quality than that with the use of constant BHF.
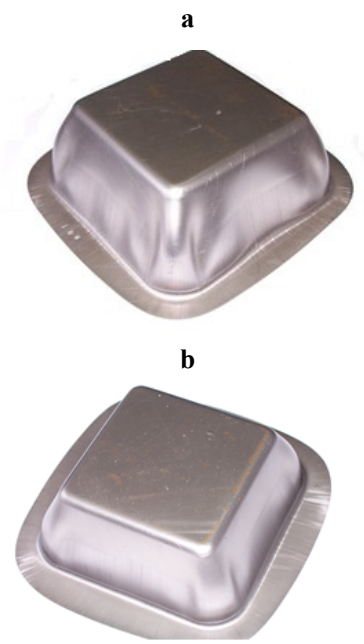

Fig. (2). The workpiece using constant BHF and VBHF comparison picture. 


\section{MATERIALS AND METHODS}

VBHF control is the core problem of controllable VBHF pressure boundary system. Current controllable VBHF pressure system research mostly adopts PID control. Although traditional PID controller algorithm is mature and stable but is designed based on the precise model of the system. The disturbance resistance and adaptability are poor and difficult to control the nonlinear, uncertain complex system. But fuzzy control for the electro-hydraulic servo system of this complex, uncertain system processing capability is strong having good control performance. Fuzzy control is an important branch of intelligent control algorithm, which is based on expert control experience to determine the control rules, which do not rely on accurate models, with flexible algorithm, especially suitable for the control of nonlinear, big lag, time-varying system, however fuzzy control algorithm has the defect that its control accuracy is not high $[4,5]$. Therefore, this article adopted PID control based on fuzzy technology. It not only maintains control of fuzzy control algorithm but also has advantages of being fast, flexible without relying on the accurate model, and inherits the advantages of traditional PID control algorithm of high precision. The two complement each other, realize the intelligent control system and achieve good control effects.

The preparation stage before forming up the blank holder in place, positions the sheet between the blank holder due to which the female dies (AUTHOR: The highlighted text is vague and needs to be rephrased for clarity). The blank holder position feedback is to control the system by the displacement sensor to determine the zero in the deep drawing control process. Deep drawing slider control by monitoring devices deteriorates until it starts drawing. In the process of deep drawing, the pressure sensor converts analog quantity into digital quantity by the $\mathrm{A} / \mathrm{D}$ converter. After processing by $\mathrm{D} / \mathrm{A}$ converter, it converts to analog signals to control the various regions of blank holding cylinder given that the variable blank-holder force completes the drawing.

As shown in Fig. (3), the process is based on the technology of fuzzy PID control VBHF system schematic diagram.

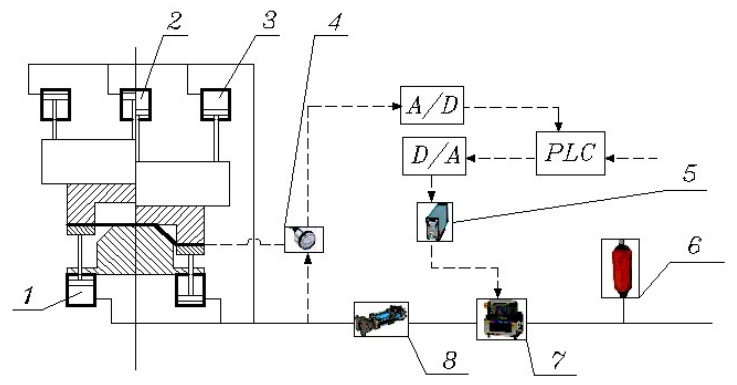

1. Hydraulic pressure pad, 2. The main hydraulic cylinder, 3. Compensation cylinder, 4. The sensor, 5. Servo valve amplifier, 6. Accumulator, 7. Electro-hydraulic servo valve, 8. Servo hydraulic cylinder

Fig. (3). Schematic diagram is based on the technology of fuzzy PID control VBHF system.
Hydraulic pressure pad for machined part of blank holder has been formed. It is equipped with the pressure sensor and the displacement sensor. In the process of blank holder formation, through sensors, it detects each value of the hydraulic cylinder pressure and displacement. The three characteristic quantities reflect the characteristics of the deep drawing process: drawing stroke $\mathrm{h}$, deep drawing force $\mathrm{P}$, and the blank-holder force $\mathrm{Q}$ respectively, convert into a voltage signal by displacement sensor and pressure sensor [6-8]. Three voltage signals by A/D converter convert analog to digital quantity of input in the computer. Computer records show that the program automatically stores these three characteristics in the computer in the form of data files, monitors real-time display $\mathrm{P}(\mathrm{h})$ and $\mathrm{Q}(\mathrm{h})$ curve in the drawing process. Control system for deep drawing stroke has feedback signal fixed by fuzzy PID control sends control signals; D/A converter converts digital quantity of the control voltage signal to analog quantity after entering the proportional amplifier. Proportional amplifier converts the control voltage signal to control current signals to control the proportional relief valve, so as to achieve control of the blank holder cylinder ejector force control of the BHF used.

\section{RESULTS}

The basic principle of PID control VBHF is based on fuzzy technology on the basis of general PID controller. Fuzzy control module works according to the system's realtime state online and adjusts the three parameters of PID, as shown in Fig. (4).

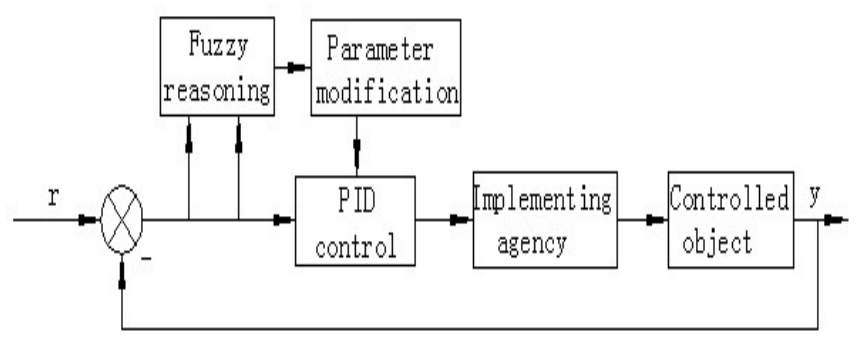

Fig. (4). Fuzzy PID process control block diagram.

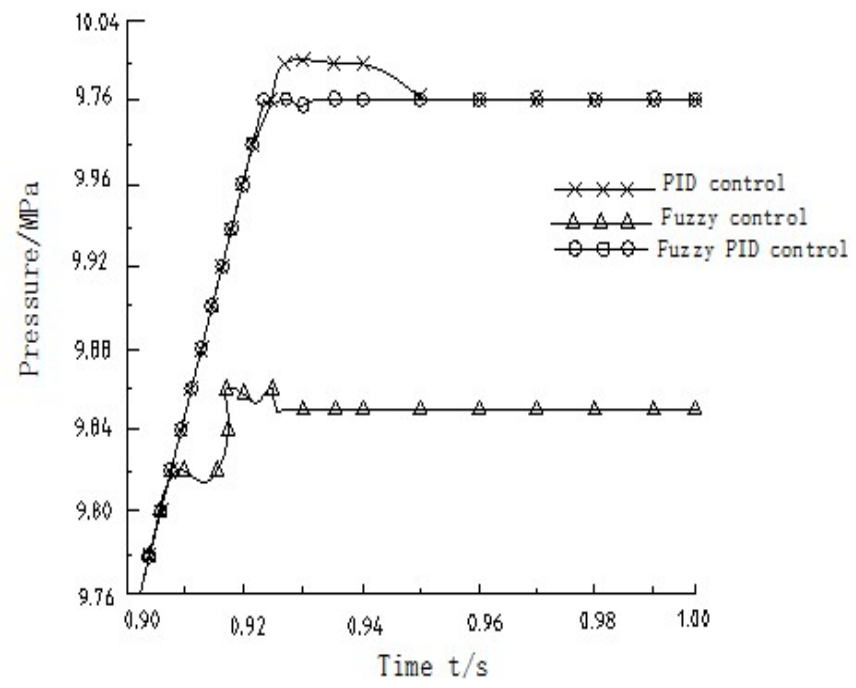

Fig. (5). System response with different control methods. 
Different control methods of the system response are as shown in Fig. (5). As can be seen from the figure, the response speed of the simple fuzzy control with simple PID control increases, but due to the lack of integral control effect, steady-state precision is low. Compared with the same

parameters of digital PID control, fuzzy PID control has several characteristics: rapid response speed, reduced overshoot amount, abating oscillation, and obvious advantages in comparison to digital PID control algorithm. Overall, the fuzzy PID control can improve the VBHF sheet metal spring back system control performance $[9,10]$.

This article adopted LabVIEW real-time data acquisition and control program system. LabVIEW control algorithm is a control strategy widely used in industrial control. It has simple principle, easy implementation, and the steady state performance is good. The traditional LabVIEW control is mainly controlled by linear process with the exact model, though in fact, most of the industrial processes with different degrees of nonlinear, time-varying parameters and fuzzy uncertainty exist. General PID controller does not have the ability of online setting parameters and the control effect is not ideal. Fuzzy control does not need precise mathematical model of controlled object, and on the basis of artificial control rules control decision table, the size of the control volume is decided by the table, with its advantage being dynamic and performance good, but is subjected to the control rules and variables quantitative level, but the steady state performance is poor [11-13]. PID control based on the technology of fuzzy using fuzzy reasoning method to realize $\mathrm{Kp}, \mathrm{Ki}$ and $\mathrm{Kd}$ online adaptive, not only maintains the conventional PID control robust features, but has more flexibility, adaptability, accuracy etc., and is a kind of relatively advanced control algorithm [14].

LabVIEW powerful data collection module combined with fuzzy control and PID control two controllers, implements simple rapid development, including data collection, data output, data display, real-time PID parameter adaptive algorithm based on fuzzy technology and can easily obtain the best control scheme [15-17]. As shown in Fig. (6), it mainly includes the command signal input module, the feedback signal input module, A/D signal conversion module, signal graphic display module, controller module, control signal output module and file record module. The

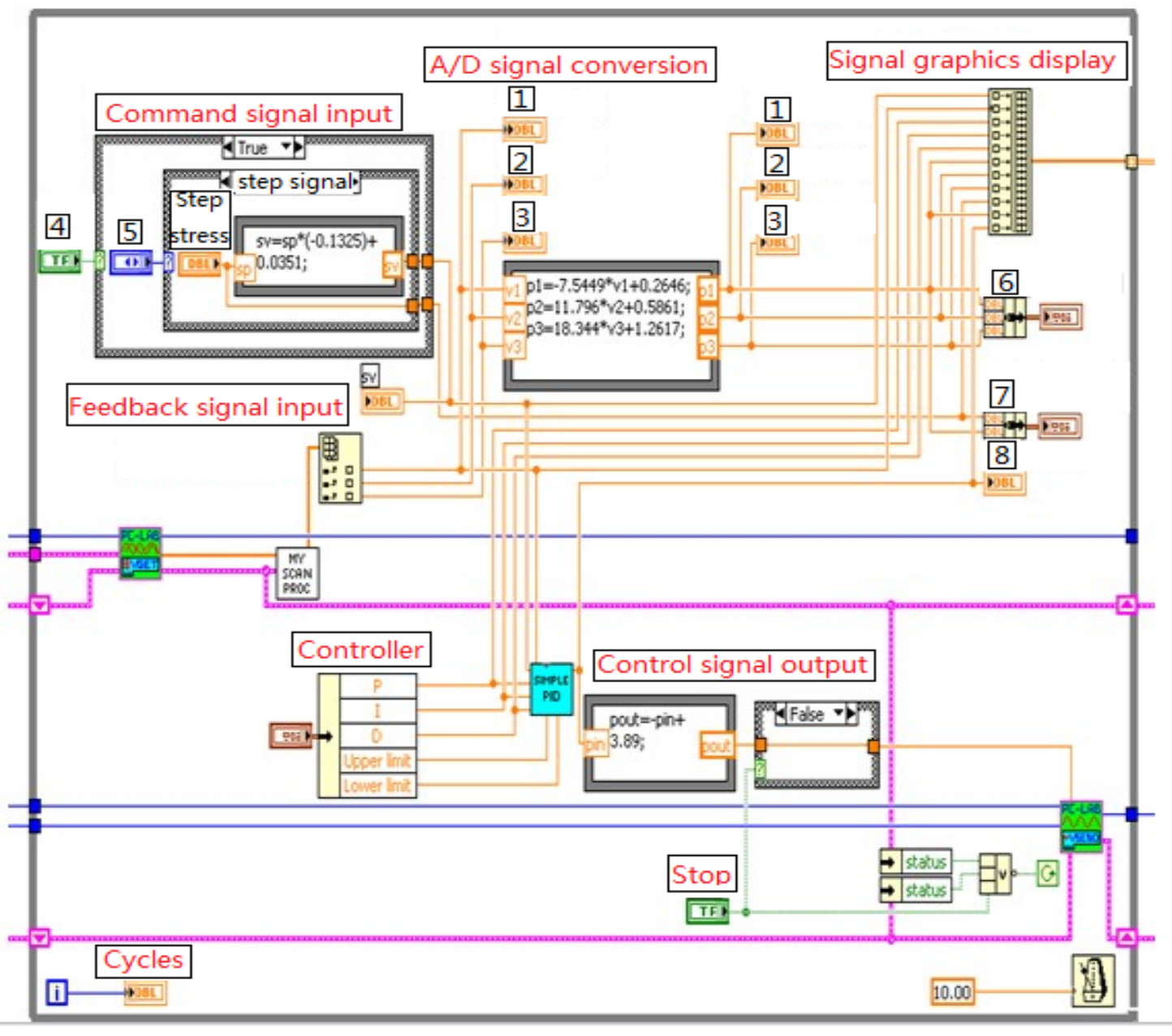

1. Recent cylinder pressure, 2. Far cylinder pressure, 3. Upstream pressure, 4. Command signal, 5. Step stress, 6. System pressure display, 7. Instruction pressure and feedback pressure display, 8. Output voltage display.

Fig. (6). LabVIEW real-time data acquisition and control process flow chart. 


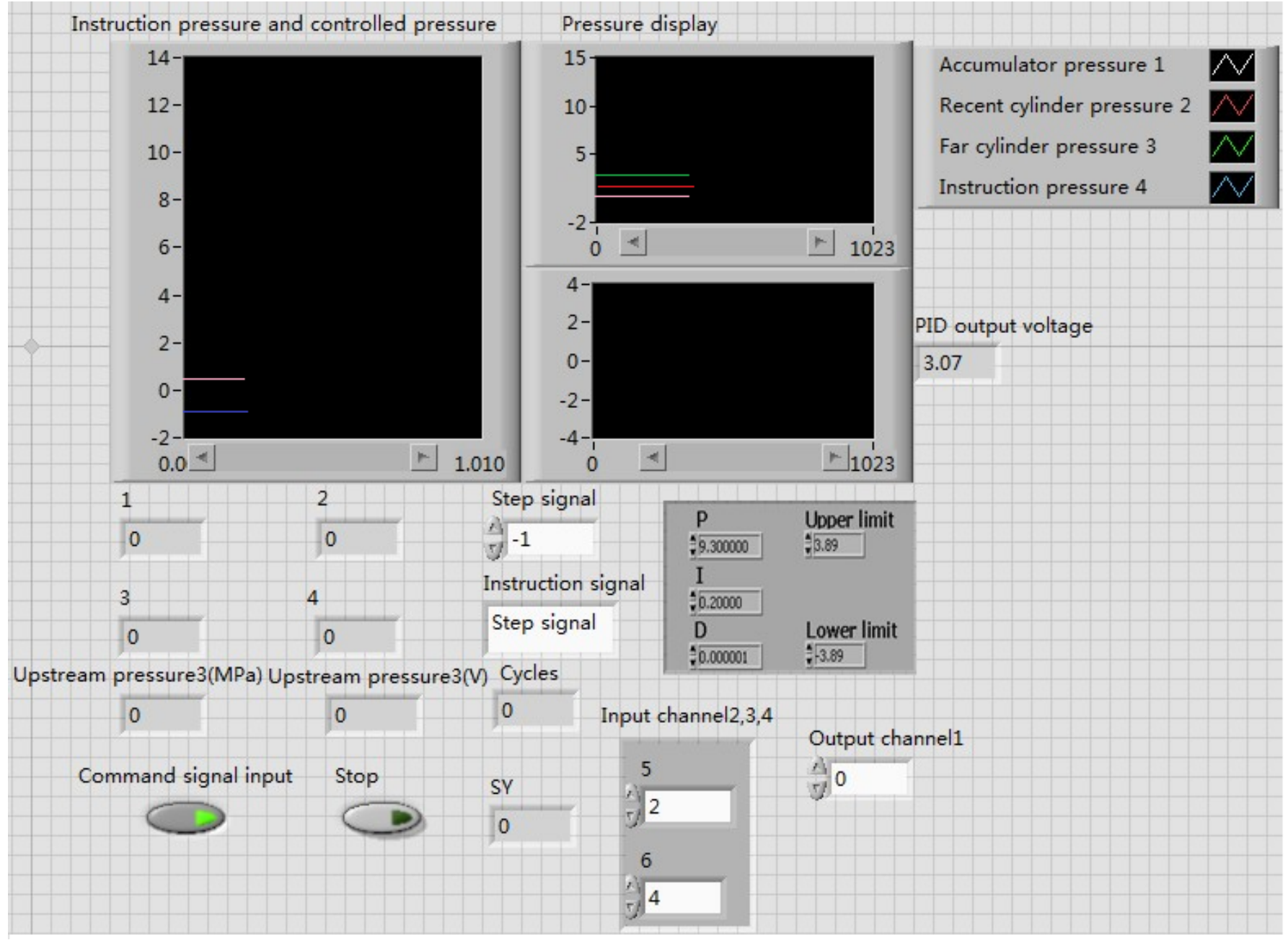

1. Recent cylinder pressure $1(\mathrm{MPa}), 2$. Recent cylinder pressure 1(V), 3. Far cylinder pressure $2(\mathrm{MPa}), 4$. Far cylinder pressure 2 (V), 5. Initial input channels, 6 . Total number of input channels.

Fig. (7). Front panel of LabVIEW Real-time data acquisition and control.

latter shown in Fig. (7) corresponds to the data flow diagram of the front panel.

Introduction of the fuzzy control algorithm in PID controller meets the requirements of quickness, stability and robustness of the control system, as LabVIEW hardware and software integration are powerful, easy to implement and make the system not only stand out in the algorithm and in the actual design but the site operation is also very feasible $[18,19]$.

\section{DISCUSSION}

In the process of sheet metal deep drawing, the blank holder device is generally required to generate enough friction resistance. BHF is an important process parameter in sheet metal forming, and changes the value of BHF as an important control mean in the sheet metal deep drawing. If the BHF is too small and unable to effectively control the flow of materials, the sheet metal is easy to wrinkle. If the BHF is too large, it can avoid sheet wrinkling, but the break down trend increases obviously. At the same time, the surface of the mold and sheet metal damage probability also increase, affecting the life of mold and sheet metal deep drawing quality. In actual production, in order to improve the productivity, the surface quality of the product is improved. As far as shaping process is concerned, the BHF parameter control is one of the most important methods to control the flow of metal to prevent wrinkling and rupturing. In fact, the adjustment process for large covering parts of the mold is mainly of BHF and involves a series of process parameters and mound parameters adjustment processes. As the equipment updates and further promotes the application of computer control, technology of variable blank-holder force can be applied not only in the automotive industry, but also in many fields such as mechanical and electrical, aviation as well as light industry, it has a wide application market [20].

In order to study the optimal variable blank holder force load curve, according to the demand characteristics of the forming force during the process of deep drawing, the different variable blank-holder force load curve is designed. Using the method of finite element simulation and experiment, analyses of all kinds of variable blank-holder force load curves impact on the quality of sheet metal 
Load mode 1

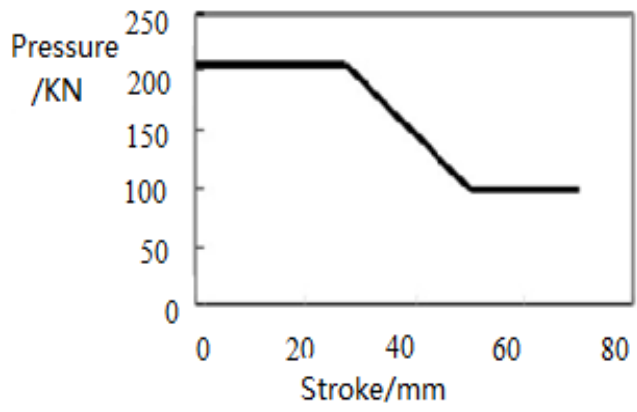

Load mode 3

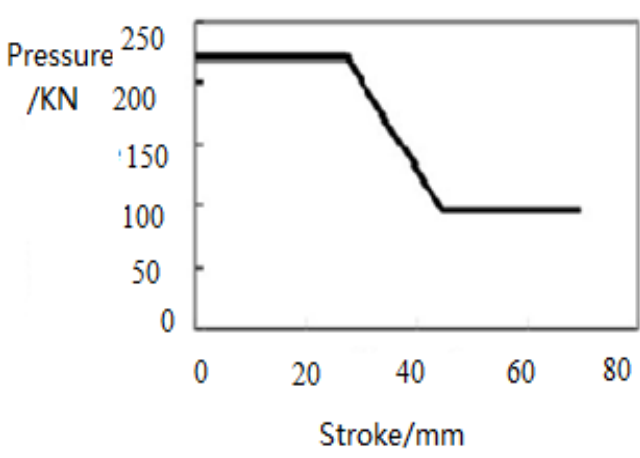

Load mode 5

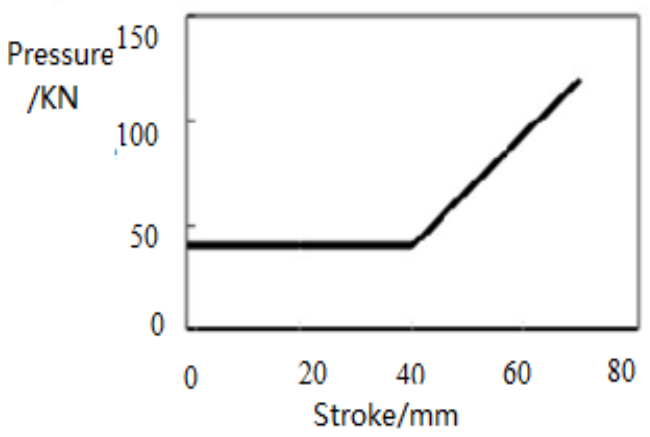

Fig. (8). Sketch of six BHF loading patterns.

forming to determine the optimal variable blank-holder force load curve. Fig. (8) shows six different loading modes.

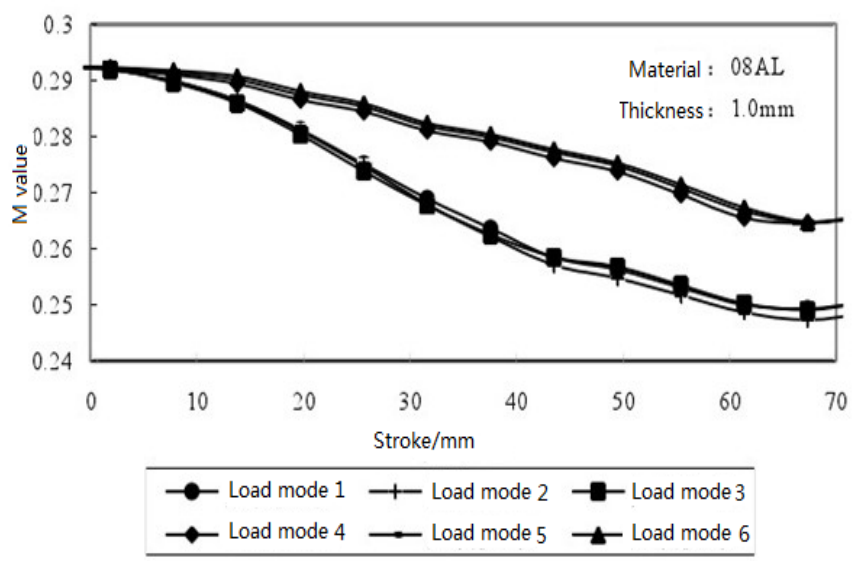

Fig. (9). Six load mode $M$ values along with the stroke change.
Load mode 2
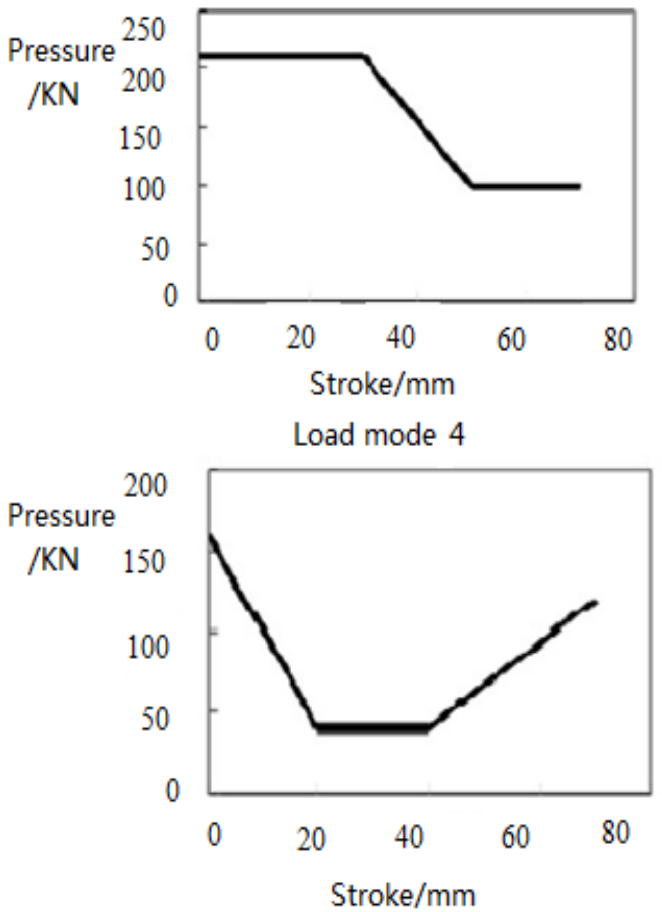

Load mode 6

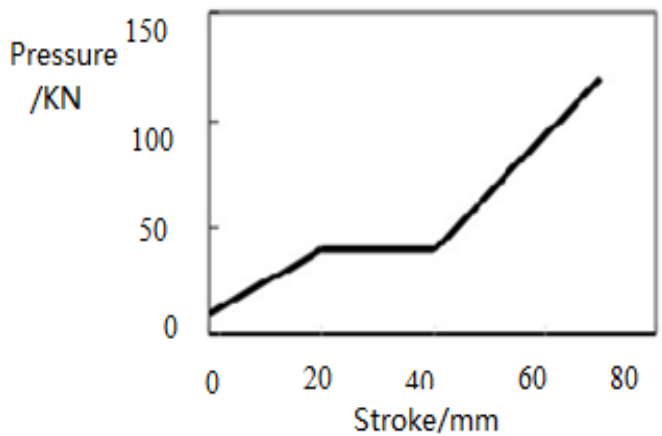

As shown in Fig. (8), loading modes 1,2,3 and load curves are roughly the same; both were initially given larger $\mathrm{BHF}$, keeping a certain stroke and after reducing the BHF, keeping the last constant. Loading mode 4 and load curve were given larger BHF earlier, being reduced to a certain value and keeping a certain stroke after continuous increase in the BHF. Loading mode 5 was given constant BHF earlier, keeping a certain stroke after continuing to increase BHF. Loading mode 6 was initially given smaller BHF, which gradually increased to a certain value, keeping a certain stroke after continuing to increase BHF [21].

Fig. (8) shows six loading models for finite element simulation. $\mathrm{M}$ value along with the stroke change trend is shown in Fig. (9). 
It can be seen from Fig. (9) that the results of using loading modes 1,2,3 were significantly better than the result of loading modes $4,5,6$. It shows that in the deep drawing process, beginning with larger blank-holder force is helpful to improve the trend of sheet metal forming quality. BHF loading modes 1,2 and 3 are identical in form. By comparing the $\mathrm{M}$ values, it can be seen that their forming qualities are significantly better than the result of loading modes 4, 5, 6 and the difference in the $\mathrm{M}$ value is small. This reflects the superiority of loading mode. As shown in Fig. (10), the BHF loading modes 1, 2, 3 have relatively positioned curves of cracked, wrinkled limit of each margin.

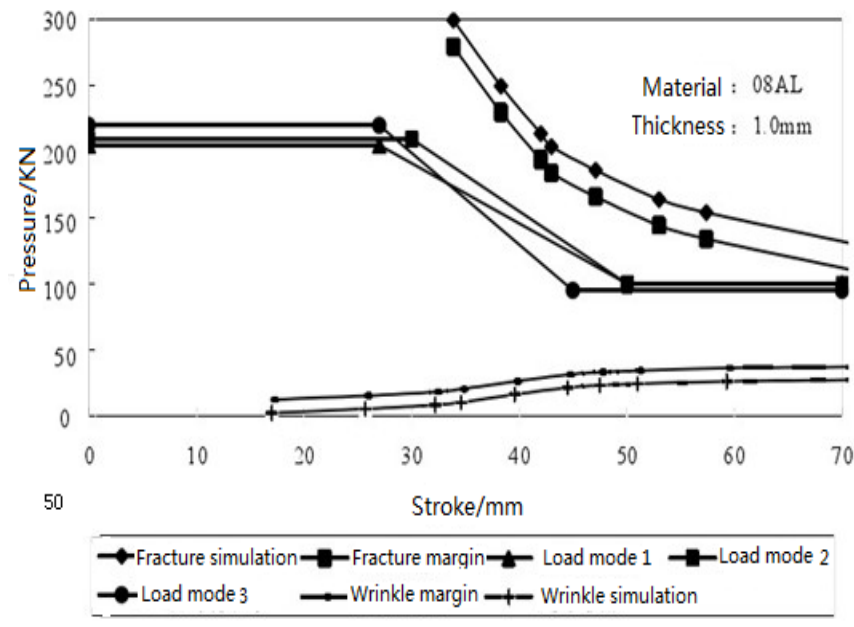

Fig. (10). Loading modes 1, 2, 3 relative position curves of cracked, wrinkled limits with each margin.

Figs. $(9,10)$ show the little difference of three loading modes reflected in the $\mathrm{M}$ value, but still differences exist. Beginning with larger BHF producing smaller $\mathrm{M}$ value, loading mode 3 is superior to the loading mode 2, and loading mode 2 is superior to loading mode 1 . Due to the large loading mode $2 \mathrm{BHF}$, later, corresponding $\mathrm{M}$ value is the least. (AUTHOR: The highlighted text is vague and needs to be rephrased for clarity.) Generally, the result of loading mode 1,2, 3 can be thought as the same; when the wrinkling critical curves are larger, load curve using critical curve along the rupture trend effect is better.

\section{CONCLUSION}

This paper is based on the technology of fuzzy PID control VBHF system research, introducing fuzzy control technology into PID control, combined with LabVIEW realtime data acquisition and control program system [22]. For finite element simulation of different loading modes, the results are analyzed and compared, eventually giving conclusions as follows.

(1) Moderate stage of increasing or decreasing the VBHF can control deformation to the direction which is advantageous to the sheet metal forming, and is based on several typical VBHF in simulation. Based on experiments, it can be concluded that in the deep drawing process, beginning with larger BHF is helpful to improve the quality of sheet metal forming. When larger than the wrinkling critical curves, load curve using the critical curve along the rupture trend effect is better.

(2) Using PID control and fuzzy control in combined proportional integral derivative control can not only obtain high steady precision, but also can achieve rapid dynamic response. So introducing fuzzy technology into PID controller not only makes the control system of dynamic and static performance improved, but the VBHF control performance of the system can also be effectively improved [23].

(3) Using LabVIEW powerful data acquisition module combined with fuzzy control and PID control two toolboxes achieves rapid development including actual parameter acquisition, control variable output, display, real-time PID parameter adaptive fuzzy control algorithm.

\section{CONFLICT OF INTEREST}

The authors confirm that this article content has no conflict of interest.

\section{ACKNOWLEDGEMENTS}

This work was financially supported by the National Natural Science Foundation of China (Grant No. 51305241) and the Science and Technology Project for the Universities of Shandong Province (Grant No. J12LA03) Taishan Scholarship Project of Shandong Province, China (No. tshw20130956).

\section{REFERENCES}

[1] G. Liu, Z. Lin, and W. Xu, "Variable blankholder force in Ushaped part forming for eliminating springback error", Journal of Materials Processing Technology, vol. 120, no. 1-3, pp. 259-264, 2002.

[2] L. Zhong-qin, W. Wu-rong, and C. Guan-long, "A new strategy to optimize variable blank holder force towards improving the forming limits of aluminum sheet metal forming", Journal of Materials Processing Technology, vol. 183, no. 2-3, pp. 339-346, 2007.

[3] W.-R. Wang, G.-L. Chen, and Z.-Q. Lin, "Application of new VBHF optimization strategy to improve formability of automobile panels with aluminum alloy sheet", Transactions of Nonferrous Metals Society of China, vol. 20, no. 3, pp. 471-477, 2010.

[4] A. J. H. Al Gizi, M. W. Mustafa, and H. H. Jebur, "A novel design of high-sensitive fuzzy PID controller", Applied Soft Computing, vol. 24, pp. 794-805, 2014.

[5] Y. Zhang, T. Yang, C. Li, and S. Liu, "Fuzzy-PID control for the position loop of aerial inertially stabilized platform", Aerospace Science and Technology, vol. 36, pp. 21-26, 2014.

[6] A. Savran, and G. Kahraman, "A fuzzy model based adaptive PID controller design for nonlinear and uncertain processes", ISA Transactions, vol. 53, no. 2, pp. 280-288, 2014.

[7] D. Pavković, S. Polak, and D. Zorc, "PID controller auto-tuning based on process step response and damping optimum criterion", ISA Transactions, vol. 53, no. 1, pp. 85-96, 2014.

[8] J. L. Calvo-Rolle, J. L. Casteleiro-Roca, and H. Quintián, "A hybrid intelligent system for PID controller using in a steel rolling process", Expert Systems with Applications, vol. 40, no. 13, pp. 5188-5196, 2013.

[9] A. Savran, "A multivariable predictive fuzzy PID control system", Applied Soft Computing, vol. 13, no. 5, pp. 2658-2667, 2013. 
[10] Y. Wu, H. Jiang, and M. Zou, "The research on fuzzy PID control of the permanent magnet linear synchronous motor", Physics Procedia, vol. 24, Part B, pp. 1311-1318, 2012.

[11] S. Dequan, G. Guili, G. Zhiwei, and X. Peng, "Application of expert fuzzy PID method for temperature control of heating furnace", Procedia Engineering, vol. 29, pp. 257-261, 2012.

[12] Z. Long, Y. Yuan, and W. Long, "Designing fuzzy controllers with variable universes of discourse using input-output data", Engineering Applications of Artificial Intelligence, vol. 36, pp. 215-221, 2014.

[13] A. G. Saravanan, and M. Rajaram, "Fuzzy controller for dynamic performance improvement of a half-bridge isolated DC-DC converter", Neurocomputing, vol. 140, pp. 283-290, 2014.

[14] C. Brown, and H. A. Gabbar, "Fuzzy logic control for improved pressurizer systems in nuclear power plants", Annals of Nuclear Energy, vol. 72, pp. 461-466, 2014.

[15] Y. Yu, Y. Zhang, X. Yuan, and Q. Hou, "A LabVIEW-based realtime measurement system for polarization detection and calibration", Optik - International Journal for Light and Electron Optics, vol. 125, no. 10, pp. 2256-2260, 2014.

[16] L. Wang, Y. Tan, and X. Cui, "The application of LabVIEW in data acquisition system of solar absorption refrigerator", Energy Procedia, vol. 16, Part C, pp. 1496-1502, 2012.
[17] Z. Wang, Y. Shang, and J. Liu, "A LabVIEW based automatic test system for sieving chips", Measurement, vol. 46, no. 1, pp. 402410, 2013.

[18] R. Jamal, "Graphical object-oriented programming with LabVIEW", Nuclear Instruments and Methods in Physics Research Section A: Accelerators, Spectrometers, Detectors and Associated Equipment, vol. 352, no. 1-2, pp. 438-441, 1994.

[19] J. M. S. Anjos, G. K. C., and E. Villani, "A proposal and verification of a software architecture based on LabVIEW for a multifunctional robotic end-effector", Advances in Engineering Software, vol. 55, pp. 32-44, 2013.

[20] Z. Q. Sheng, S. Jirathearanat, and T. Altan, "Adaptive FEM simulation for prediction of variable blank holder force in conical cup drawing", International Journal of Machine Tools and Manufacture, vol. 44, no. 5, pp. 487-494, 2004.

[21] H. Koyama, R. H. Wagoner, and K. -I. Manabe, "Blank holding force control in panel stamping process using a database and FEMassisted intelligent press control system", Journal of Materials Processing Technology, vol. 152, no. 2, pp. 190-196, 2004.

[22] U. Zuperl, F. Cus, and M. Milfelner, "Fuzzy control strategy for an adaptive force control in end-milling", Journal of Materials Processing Technology, vol. 164-165, pp. 1472-1478, 2005.

[23] X. Dong, Z. Jian-qu, and W. Feng, "Fuzzy PID control To feed servo system of CNC machine tool", Procedia Engineering, vol. 29 , pp. 2853-2858, 2012.

(C) Su and Zhao; Licensee Bentham Open.

This is an open access article licensed under the terms of the Creative Commons Attribution Non-Commercial License (http://creativecommons.org/licenses/by-nc/4.0/) which permits unrestricted, non-commercial use, distribution and reproduction in any medium, provided the work is properly cited. 